\title{
An Examination of the Relationship between High School Students' Self-efficacy Perceptions Concerning Electromagnetism and Their Academic Success
}

\author{
Sevim Bezen ${ }^{1^{*}}$, Işıl Aykutlu ${ }^{1}$, and Celal Bayrak ${ }^{1}$ \\ ${ }^{1}$ Hacettepe University, Faculty of Education, Ankara, Turkey
}

\begin{abstract}
In the study, "Magnetism and Electromagnetic Induction" topic, which is part of the unit titled Electricity and Magnetism within the 11 th grade Physics program that came into effect in 2013. In this study that aims to examine the relationship between high school students' selfefficacy perceptions concerning electromagnetism and their academic success, study group consists of students who are enrolled at the 11th grade of Anatolian high schools in Ankara. Selection criterion was that students have completed covering "Magnetism and Electromagnetic Induction" topic. Within the scope of the study, answers to following questions were sought: "What is the self-efficacy level of 11th-grade students concerning electromagnetism?", "What is the academic success levels of 11th grade students concerning electromagnetism?" and "Is there a meaningful relationship between students' perception of self-efficacy concerning electromagnetism and their academic success?". At the end of the study, it was revealed that students experience problems with electromagnetism, and thus they do not have a high perception of self-efficacy.
\end{abstract}

\section{Introduction}

Learning is a complex and multidimensional process. In this process, cognitive and sensory proficiencies affect learning. Among sensory factors are proficiencies, beliefs, thoughts, and motivations [1]. Self-efficacy, which is one of the motivational sources, shapes people's thoughts [2] self-efficacy is among the basic factors that affect the realization of learning objectives and student success during all learning steps. With self-efficacy perception students' beliefs concerning what they could do under various circumstances are revealed [1]. It can be said that students with high self-efficacy perception are more determined, willing, and insistent on succeeding [3]. It can be said that there is a difference between a student who says I can and who says I cannot in their tendency to learn. In this respect, there is a positive relation between self-efficacy and academic achievement [4]. In general, it is expected that students with high self-efficacy perception have a high academic success [2], because it is known that with the high level of self-efficacy perception students

* Corresponding author: sevimbezen@hacettepe.edu.tr 
will have a higher motivation and they will focus on the topic more, and they will be more willing to try to learn. At the same time, it is thought that students should reach a consistent result between their self-efficacy and academic success in order to manage their own learning processes $[5,6]$. In literature, there are studies on whether high school students' self-efficacy and academic success can be predicted. At the end of these studies, it was seen that self-efficacy is a significant variable that predicts student success especially in the fields of mathematics and positive sciences [7, 8, 9]. In this study, electromagnetism is taken as the subject matter in the examination of the relationship between self-efficacy perception and success. It this thought that students experience difficulties in learning electromagnetism as a topic, and it is thought that the reason for this is that students have a low self-efficacy perception on this topic [10]. Indeed, electromagnetism as a topic includes such abstract concepts that cannot be explained by direct observation, and these concepts are used in various places and fields such as compasses, electricity, loudspeakers, usb's, and many other fields [11]. Students get the chance to employ their skills of threedimensional thinking and visualization for the first time during this particular topic [12]. At the same time, electromagnetism affects not only the lives of humans but also the lives of other beings. At this point, the importance of teaching the basic concepts of this topic is obvious [13]. To this end, in this study, "Magnetism and Electromagnetic Induction" which is included in the 11th grade Physics curriculum. In the study, the aim was to examine the relationship between academic success and 11th graders' self-efficacy perceptions concerning electromagnetism, and answers to following questions were sought:

What is the self-efficacy perception of 11th graders concerning electromagnetism?

What is the academic success of 11 th graders concerning electromagnetism?

Is there a meaningful relationship between 11th graders' self-efficacy perceptions concerning electromagnetism and academic success?

\section{Methodology}

\subsection{Pattern}

This study was patterned in accordance with the relational survey model because the aim was to describe the relationship between self-efficacy perception levels of students concerning electromagnetism, which is part of the physics course, and their academic success levels. In this model, the aim is to describe the situation as it is without any external influence or interference to the circumstances of students [14]. In the study, quantitative data gathering and analysis methods were used.

\subsection{Sampling}

Study universe consists of $11^{\text {th }}$ grade science and math students during the 2017-2018 academic year Spring semester in Ankara. Sampling was formed with the participation of a total of 200 students from 3 high schools. In the study, criterion for inclusion was that "Magnetism and Electromagnetic Induction" topic should be completed in class. At the end of the data gathering process, data obtained from 200 students were taken into account.

\subsection{Data gathering tools}

Data of the study were gathered with the help of "Self-Efficacy Form Concerning Electromagnetism" and "Electromagnetism Conceptual Success Test." In this respect, the study was limited within the frame of students' perception of their self-efficacy and their 
academic success. The self-efficacy form, which was developed by the researchers, was designed by examining the outcomes that exist within the field of this particular topic, and giving behavior expressions that could signify the acquisition of these outcomes (I can write down ...., I can understand ...., etc.). Items in the form were graded as "Always, Often, Undecided, Rarely, and Never." Moreover, at the beginning of the form there was an explanation part where the aim of the study was explained; and the positive and negative items were put randomly in the form so as not to cause any manipulation. Then, this selfefficacy form was examined by three experts who hold $\mathrm{PhDs}$ in this field. Based on the views and suggestions of the experts, the form was re-arranged, and it took its final form. The final form consists of 15 items. Cronbach alpha coefficient was calculated to be 0.84 after the reliability test of the measurements obtained from the form. In this respect, it can be said that the measurements have a good reliability level. Another data gathering tool to be used in the study was the "Electromagnetism Conceptual Success Test," designed by [15]. Electromagnetism Conceptual Success Test was designed based on the outcomes that are given in the curriculum, and it consists of 12 multiple-choice questions. The first four questions in the form are graded five points, and the other questions are 10 points. Reliability coefficient of the "Electromagnetism Conceptual Success Test" was found to be 0.768 .

\subsection{Process and data analysis}

Because the study was conducted according to relational survey model, the self-efficacy concerning electromagnetism form and conceptual success test were handed to the students all together. Data obtained from the study were first of all arranged and the forms of those who completed both forms completely were taken into consideration. Then, students' answers were examined by the researchers separately and they were scored. In the success test, students' scores were calculated based on their answers and their final success scores were calculated. The lowest score students can get from the success test is 0 , and the highest they can get is 100 . In the form with which their self-efficacy perception is determined, positive and negative items were scored in reverse in that the lowest selfefficacy perception was given and coded as 1 , and the highest five. Then, total score each student receives from the self-efficacy form was calculated. According to this, high scores students get in this form indicate high self-efficacy perception, and low scores indicate low self-efficacy perception. Lowest possible score students may get from the self-efficacy form is 15 , and the highest possible score is 75 . Interval coefficient of this form according to this was calculated to be 12: Never (1): 15-27, Sometimes (2): 27-39; Undecided (3): 3951; Frequently (4) 51-63; Always (5): 63-75. Data were analyzed through SPSS in accordance with quantitative data analysis techniques. In this respect, students' selfefficacy levels and success levels were analyzed by using descriptive statistical analysis techniques (arithmetic average, standard deviation), and the relationship between selfefficacy scores and success scores was analyzed with the help of Pearson correlation coefficient technique.

\section{Findings}

In the study, findings of the study, which were obtained after the data analysis collected through "Self-Efficacy Form Concerning Electromagnetism" and "Electromagnetism Conceptual Success Test," were gathered under three headings according to the research questions. Under the first and second headings were presented the findings obtained from the success test and the self-efficacy form as a result of descriptive statistics; and under the 
third heading were given the correlation analysis results that examine the relationship between students' self-efficacy perceptions and their success scores.

\subsection{Findings concerning self-efficacy perception levels}

In this section, an answer to the following research question was sought: "What is the level of self-efficacy perception of $11^{\text {th }}$ graders concerning electromagnetism?" First of all, students' scores concerning self-efficacy form were analyzed through descriptive statistics analysis in order for the research question to be answered, and results of the analysis can be seen in Table 1.

Table 1. Minimum, Maximum, Arithmetic Average, Standard Deviation Values of Students' SelfEfficacy Scores.

\begin{tabular}{|c|c|c|c|c|c|}
\hline & $\mathbf{n}$ & Minimum & Maximum & Arithmetic Aver. & Standard Deviation \\
\hline $\begin{array}{c}\text { Scores of } \\
\text { Self-Efficacy } \\
\text { Form }\end{array}$ & 200 & 22.00 & 79.00 & 53.03 & 10.24346 \\
\hline
\end{tabular}

According to Table1, the lowest score students got from the self-efficacy form is 22, and the highest is 79. Arithmetic average of their scores is 53.03. arithmetic average of students' self-efficacy perception in the sampling falls in "Frequently (3): 51-63" category. According to this, it can be said that students' self-efficacy perception level is intermediate.

\subsection{Findings concerning success levels}

The second research question was "What is the academic success of $11^{\text {th }}$ graders concerning electromagnetism?" Descriptive statistics analysis results concerning student success, which was measured by the success test designed for electromagnetism, are given in Table 2.

Table 2. Minimum, Maximum, Arithmetic Average, Standard Deviation Values of Students' Success Test Scores.

\begin{tabular}{|c|c|c|c|c|c|}
\hline & $\mathbf{n}$ & Minimum & Maximum & Arithmetic Aver. & Standard Deviation \\
\hline $\begin{array}{c}\text { Success Test } \\
\text { Scores }\end{array}$ & 200 & 00.00 & 80.00 & 36.13 & 19.234 \\
\hline
\end{tabular}

When Table 2 is examined, it can be the lowest score students got from the test is 0 , and the highest is 80 . Arithmetic average of their scores is 36,13 . Since students can get 0 the lowest and 100 the highest from the test, it can be said that students' general success levels are low.

\subsection{Findings related to the relationship between self-efficacy and success}

The third research question was "Is there a meaningful relationship between $11^{\text {th }}$ graders' self-efficacy perception concerning electromagnetism and their success levels?" Whether the there is a meaningful relationship between the two, it was tested by calculating the Pearson moments multiplication coefficient. Analysis results are given in Table 3. 
Table 3. Correlation Results between Students' Self-Efficacy Perception and Their Success Level Concerning Electromagnetism.

\begin{tabular}{|c|c|c|}
\hline \multirow{3}{*}{ Success } & \multicolumn{2}{|c|}{ Self-Efficacy Perception } \\
\cline { 2 - 3 } & $\mathrm{r}$ &, $279^{* *}$ \\
\cline { 2 - 3 } & $\mathrm{p}$ &, 000 \\
\hline$* * \mathrm{p}<.01$ & $\mathrm{n}$ & 200 \\
\hline
\end{tabular}

According to Table 3, there is a positive, low level yet meaningful relationship between students' self-efficacy perception concerning electromagnetism and their success levels $(\mathrm{r}=0,279 ; \mathrm{p}<.01)$. This relationship can be read as follows: the more self-efficacy students have the more successful they will be; likewise the less self-efficacy they have, the less successful they will be.

\section{Conclusion and discussion}

In this study, $11^{\text {th }}$ graders' self-efficacy perception concerning electromagnetism and their success levels as well as the relationship between the two was examined. Findings of the study show that students' success levels in electromagnetism are generally low and their self-efficacy levels are intermediate. It was determined that the relationship between the two is low but meaningful in a positive way. According to this, it can be said that students' self-efficacy perception and success increase or decrease in parallel to their each other. As far as electromagnetism is concerned, it is known that it is part of daily life and that learning it is effective in daily life [11]. However, finding of the result shows that students have a low success level on this topic. This makes one think that objectives have not been properly achieved in physics classes concerning electromagnetism. It can be argued that problems faced in this topic, which plays an important role in the acquisition of basic knowledge and skills of the field, can have a negative effect in students' future learning experiences. It is thought that this may stem from teachers, student, and the learning process. When literature is examined, there were such expressions that indicate the need for preferring active learning methods to eliminate such problems [16]. It is contended that by using active learning methods success and attitude of students towards the topic would increase. Moreover, literature shows that studies on electromagnetism are generally on conceptual comprehension $[17,18]$. It can be said that the reason for this is the fact that electromagnetism includes abstract concepts and that it is difficult to learn electromagnetism conceptually. In addition to this, no study has been found that examine the relationship between high school students' self-efficacy perceptions and their academic success levels. However, it is seen that the result of this study, which contends that there is a meaningful relationship between self-efficacy perception and academic success, is supported by other studies conducted with high school students [7, 8, 19]. For example, [20] and [21] researched whether students' self-efficacy beliefs is a predictor of their success in mathematics classes. At the end of the study, it was revealed that self-efficacy beliefs have an effect on academic success. Likewise, [9] and [22] researched the effect of self-efficacy belief on success in science classes, and they reached the same conclusion. In this respect, it is thought that students' self-efficacy perceptions should be strengthened, and that students should be able to determine their own objectives concerning these. Students should be supported in selecting an appropriate strategy, in progressing with the way they have planned things, and in being able to evaluate the conclusion they have reached. At the same time, it can be suggested that new studies may focus on putting forth a model for determining which factors other than self-efficacy perceptions affect students' success in what levels and in which ways. Since self-efficacy is a factor that affects the whole learning process, it is expected that this relationship between self-efficacy and 
success will be reflected in the attitude towards electromagnetism or the physics classes. In this respect, examining the relationship between self-efficacy, success, and attitude all together would be good, and it is believed that such studies will fill a gap in the field.

\section{References}

1. A. Bandura, Self-efficacy: The exercise of control (W. H. Freedman and Company, 1997).

2. D. H. Schunk, Educational Psychologist, 26 (1991).

3. H. Margolis, P. P. Mccabe, Intervention in School and Clinic, 41, 4 (2006).

4. S. Kurbanoğlu, Information World, 5, 2 (2004).

5. F. Pajares, M. D. Miller, Journal of Educational Psychology, 86, 2 (1994).

6. F. Pajares, Contemporary Educational Psychology, 21 (1996).

7. J. Gold, The relationship between self-efficacy and achievement in at-risk high school students (Walden University College of Education, 2010).

8. Ş. Keleşoğlu, A study on the predictive power of the variables of learning styles, academic self- efficacy, the scores of level determination exams and student characteristics in predicting the academic success of 1st grade of high school (Ankara University, Ankara, 2011).

9. M. Pektaş, Some of factors affecting science achievement in sampling of Turkey that trends in International Mathematics and Science Study (TIMSS) (Hacettepe University, Ankara, 2010).

10. N. Yiğit, A. R. Akdeniz, Ş. Kurt, Fizik öğretiminde çalışma yapraklarının geliştirilmesi [Development of working leaves in physics teaching] (Maltepe University, İstanbul, 2001).

11. Ş. Aycan, A. Yumuşak, National Education, 159 (2003).

12. E. Bagno, B. S. Eylon, American Journal of Physics, 65, 8 (1997).

13. R. Chabay, B. Sherwood, American Journal of Physics, 74, 4 (2006).

14. N. Karasar, Scientific research method (Nobel Company, Ankara, 2005).

15. Ü. Turgut, R. Salar, A. Çolak, Bayburt Eğitim Fakültesi Dergisi, 11, 1 (2016).

16. F. Akşit, The effect of active learning on academic success in geography teaching (Gazi University, Ankara, 2007).

17. G. M. Paulus, D. F. Treagust, Journal of Science and Mathematics Education in South East Asia, 14, 2 (1991).

18. A. Hapkiewicz, MSTA Newsletter, 28 (1992).

19. J. Saunders, L. Davis, T. Williams, J. H. Williams, Journal of Youth and Adolescence, 33, 1 (2004).

20. F. Barış, The investigate of TIMSS-R and TIMSS-2007 examinations for the purposes of factors that affected the student's achievement (Hacettepe University, Ankara, 2009).

21. S. Akarsu, A cross-national study on self-efficacy, motivation and pisa 2003 mathematics literacy: Turkey and Finland (Abant Izzet Baysal University, Bolu, 2009).

22. A. Mutlu, Self-efficacy, learning strategies, task value and gender: Predictors of $11^{\text {th }}$ grade biology achievement (Middle East Technical University, Ankara, 2012). 